\title{
Representation of Socio-Economic Activities and Conflict in Traditional Oral Narratives of the Tharaka People in Kenya
}

\author{
Prof. Colomba Kaburi Muriungi (PhD) \\ Department of Humanities, Chuka University, \\ P.O Box 109-60400, CHUKA, KENYA.
}

\begin{abstract}
This study looks at oral narratives collected from the Tharaka people who live on the eastern region of Kenya, in Tharaka Nithi County. The Tharaka people were from time immemorial pastoralists and peasant farmers, who often had conflicts with the neighboring communities and amongst themselves. This background was often reflected in their oral literature and this is what this research pays attention to. My thesis in this paper will be that oral literature in any community acts as a memory reservoir for the community. The research explores how oral narratives help to represent the society's economic activities and in re-narrating and configuring the types of conflict that the community experienced in the past. The narratives were collected through identifying expert oral narrators and recording oral narratives from them. Narratives were purposively sampled to get a population of narratives enough for the analysis done in this paper. The study concludes that preservation of such genres helps in not just representation of the economic activities of a community but they also help in preserving the community's past experiences, specifically, the history of conflict and conflict resolution in pre-literate communities in Africa.
\end{abstract}

Key Words: Oral Narratives, Tharaka Community, Conflict, economic activities, Kenya

\section{INTRODUCTION}

According to Joshua Project (1994) conducted on communities and their languages, the Tharaka people occupy the low plains between the slopes of Mount Kenya in the west and the upper Tana River in the east. Their history of immigration dates back to the spread of the Bantu people from Southern Africa. According to Tharaka oral history, for a long period of time, the Tharaka people lived in villages because village life was considered to preserve their tradition and culture. In terms of economic activities the Tharaka were farmers. They concentrated on keeping cows, goats and sheep, and growing crops like sorghum, millet, peas, cow peas, sun flower and cotton. Some of these economic activities were often reflected in their oral literature.

In defining oral literature Adejumo (2009) asserts that oral presupposes a creative text delivered by the word of mouth. It refers to the heritage of imaginative verbal creations, stories, folk-beliefs and songs of preliterate societies which have evolved and passed on through the spoken word from one generation to another. According to Chesaina (1994) oral narratives, songs, proverbs and riddles were created by people and handed down from generation to generation during traditional historical period. Chesaina adds that these oral genres can speak to us and to our children through generations because these genres are embedded with people's way of life. In Mirambo's words (2010), Oral literature embodies history, cultural values, philosophy and beliefs of a people. Mirambo further notes that this literature teaches what society likes and what it hates. According to Shitemi (2009) oral literature is fused and integrated in peoples' daily interaction through communication, language use and other modes of transmitting knowledge like norms and social ethics. In the 
changing times, where innovations and technology is at its height, the oral art forms tend to move to another level by being embedded in these technologies. The modern oral transmissions are infused with modern innovative vigor seen in modern gadgets used in communication like mobile phones. Therefore just the way grandparents used to narrate the stories of war, conflict and economic activities in the traditional set up, modern issues of conflict like terrorism, drought, war, etc. trend on modern means of passing messages like through the television, twitter, SMS and WhatsApp, to mention only a few.

This paper overlooks the abovementioned modern means of passing information and goes back in time to examine how narratives from the Tharaka community acted as memory reservoirs for the community. The paper demonstrates that these narratives help in revealing not just communal activities there in, but they also expose the kind of conflicts that existed between communities and amongst the members of the community, and in addition, how such conflicts were resolved. The discussion looks at narratives with both animal characters and human characters and generalizes the encounters of these characters, as portraying the societal experiences. The results of this analysis are therefore in two parts. First, the communal activities revealed and second, the conflict exposed, which implies violence. In the process the discussion exposes conflict resolution methods and the lessons learnt from the conflicts. The study concludes that preservation of such genres helps in maintaining the history of preliterate communities in Africa, such as the Tharaka of Kenya. This study can therefore act as a basis for possible future studies that can endeavor to compare the effectiveness of passing messages through oral stories in both traditional and moderns set ups, especially for the Tharaka community, which is under-researched.

\section{THE GAP, METHOD AND THEORY}

For a long time in Africa, oral literature has been studied as a means to understanding the activities of the preliterate societies. Many communities in Kenya have had their oral literature in all genres recorded for safe keeping. However, the oral literature of the Tharaka community has hardly been recorded and so little is known about their oral genres, which means there is a risk of this literature disappearing into oblivion. This paper is part of a broader project of collecting genres of oral literature of the Tharaka people. The current study has singled out oral narratives for the purpose of this discussion.

The narratives discussed here were collected from five participants; three from Tharaka North: (Karemu, 45 years; Nthiga, 60 years; Munyi, 75 years) and two from Tharaka South (Nkuru 35, years; Nyaga, 65 years). This age bracket was selected for a fair representation of both the old and the young. There were many narratives that were collected, since this is an extensive project, but only ten (10) are utilized here. These narratives are:

1. "The Lion and the Cow" - by Munyi from Tharaka north

2. "The chicken and the Eagle" - by Nkuru from Tharaka south

3. The Snake and the Frog" - by Karemu Tharaka north

4. "Ciari and Kamankuura" - by munyi

5. "Karauki and the Raiders" - by Munyi

6. "The Lion, The Hare And The Monkeys - by Nyaga Tharaka South

7. "Utethio's Family and the Giant" - by Nyaga

8. "A Man and a Giant" - by Karemu

9. "The Ogre and The Girl" - by Nkuru

10. The Chosen Ones - by Nthiga from Tharaka North

Nine out of the ten titles have an implied relationship between the characters, and, as we will see later in this discussion, these relationships sometimes become the source of conflict, which 
is a major aspect of discussion this paper, while other times conflict comes from outside the relationship, affecting the perfect coexistent between the characters.

The paper utilizes functionalism theory and argues that oral narratives were used for specific purposes in all societies in Africa. One of the early functionalist theorists, Malinowski (1944) emphasizes that culture is essentially an instrumental apparatus by which man is put in a position to cope with concrete, specific problems that face him in his environment in the course of satisfaction of his needs; that, culture is a system of objects and activities in which every part exists as a means to an end and the various elements are interdependent. Culture can therefore be analyzed into a number of aspects such as education, social control, economics and systems of knowledge, believes morality and modes of creative expression which contribute towards a cohesive society. Malinowski's assertions will be useful in analyzing how the narratives discussed here serve to demonstrate the cohesiveness of the society before conflict sets in.

Kuper and Kuper (1985) argue that functional analysis is used in social sciences to inquire why particular features of a system persist by locating them in the wider system. By so doing function is ascribed to a particular practice or item. Such functions ensure in helping survival in the society. The stories analyzed here help to show the functions of each activity the characters are involved in, for example hunting helps in bringing food to the table. The narratives themselves serve a function of showing the communal organization. This is in agreement with Parsons (quoted in www.sociology.org.uk, 2005), ${ }^{1}$ who argues that all parts of the society have a purpose or a function and certain needs. This means each institution in the society faces certain problems that have to be solved if it has to exist and function properly. First, there is goal attainment, meaning there is need to set goals for human behavior and also determine the means by which these goals can be achieved. Second, there is adaptation which involves procuring the means to achieve valued goals by providing the physical necessity of an institutional life. Third is integration of people so that they can belong and one of the ways of achieving this is giving them something they can hold in common such as values and believes. Fourth, is the need to develop social mechanisms to manage tensions, motivate people and resolve interpersonal conflicts within an institution. These assertions will be useful in analyzing the benefits of the narratives under discussion to the audience and the society at large.

\section{SOCIO-ECONOMIC ACTIVITIES VISIBLE IN THE NARRATIVES}

Oral literature is important in communicating ideas, emotions, beliefs and appreciation of life. This literature defines, interprets, and elaborates on the society's vision of reality and the dangers in the world. In this way, storytelling provides a sense of history and continuity for the concerned communities and also exposes the lifestyles of such communities.

As already mentioned, the Tharaka community was traditionally involved in different economic activities and many of the narratives in this discussion introduce some of the economic activities like hunting, gathering and farming, which are exemplified by both animal and human characters. For example, in the story the "The Lion and the cow" narrated by Munyi, we see mother Lion and mother cow being friends and often going to hunt in order to provide for their offspring. Relationship between human beings and animals comes out in this story because when the lion differs with the cow after the death of lion's cub, the cow runs away to man for protection from the angry lion. In his functionalist approach to the society,

${ }^{1}$ Any subsequent mention of Parsons in this article will be referring to this cite. 
the fourth aspect that Parsons identifies in solving societal problems is the need to develop social mechanisms to manage tensions, motivate people and resolve interpersonal conflicts within an institution. In this narrative there is a twist in the story which allows the cow to survive the wrath of the lion. While this is an etiological narrative showing management of a crisis and further explaining why cows live with human beings, it is important if demonstrating how conflicts were solved; in this instance by the guilty character withdrawing, because conflict arises after the cow's calf kills the lion's cub. The initial relationship between the lion and the cow reflects cohesiveness brought about by fulfillments of the characters' needs as suggested Malinowski (1944). However when the balance is tilted by the cub's death conflict sets in. The running away of the cow to man demonstrates the hierarchy of power in the society; that man was more knowledgeable and protective to the cow as compared to the furious lion. Such a narrative further demonstrates that there was bound to be frictions in relationships regardless of how friendly characters were.

The story "The Snake and the Frog' narrated by Karemu also introduces farming as an economic activity. The frog and the snake are friends and they seem to be the only hardworking animals in the setting of this narrative. Hard work and putting food on the table for the two characters bring peace in their relationship. The two are experts in tending bananas, while the other animals idle around and want to steal from the farm owned by the frog and the snake. Because of its venom, the snake guards the bananas from other animals who may intend to steal the fruits of their sweat. There is an idea of punishment of the lazy characters through the bite from the snake which can be read as a lesson for idle people in the community. Such narratives were useful in encouraging the spirit of hard work. While the snake is seen in many instances where it appears as evil, in this instance the venom is used to guard what is rightly owned. Food and food shortage seem to be source of the conflict in this story, with the conflict coming from outside the friendship circle of the frog and the snake. According to Kuper and Kuper (1985), function is ascribed to a particular practice or item for survival in the societal. The lazy animals in this case want to survive by stealing while the hardworking maintain their property by being strict. This creates a norm of behavior that should be followed in that context. Such narratives help in encouraging the act of working hard to attain what is yours, therefore shaping the individual in the society. Therefore animal characters in traditional oral narratives are types to understand the society, the relationship between members of the society, and in the context of this article, the causes of conflict between members of the society.

The two stories "Ciari and Nkamankura and "Karauki and the Raiders" both narrated by Munyi demonstrate that the Tharaka people were also livestock keepers because their neighbors raided them - bringing inter- tribal conflict. Conflict in this sense comes from outside the community circle. In the two stories, aspects of raiding are introduced and in addition, the narrative "Karauki and the Raiders" demonstrates the belief systems of the Tharaka. The power of traditional medicine man is evoked, as it is he who gives the warriors three baskets that would turn into a valley, sand and water at different points during the rescue mission, to distract the movement of the raiders, thus rescuing Karauki. The warriors eventually get home safe with the Karauki when the raiders are drowned in the river that appears when the third basket is unleashed. Warriors are here presented to have been a necessity in the traditional Tharaka community as they helped save the community from calamities. In both stories it is the warriors that save the cows and rescue the girl respectively. However, in "Ciari and Kamankuura" there is an aspect of selfishness of characters that produce a series of demands before the cows would be rescued. When Kamankuura is asked to follow the raiders who hailed from the neighboring community to bring back the cows, he demands that he should have a dance with Ciari before doing so since he had desired her beautiful body for a long. 
Kamankuura's demand turns into a chain of demands where Ciari desires to box the cat before dancing with Kamankuura and the cat demands milk from the cow, which now calls for the whole society to come together to look for a solution. The eagle is then summoned and convinced to cut the sky to bring down rain that would make grass grow so that the cow would eat and get a calf to beget the milk that the cat would drink and allow to be boxed by Ciari for her to dance with Kammankura who would subsequently go after the raided cows. This chain of events represents how people take advantage of situations, putting the whole society into crisis. At another level however, it helps in calling for responsibility; the story educates that it was the whole society's obligation to tackle conflict that affected it. Such a narrative is a lesson in today's society where conflict is ripe. This narrative therefore shows that the Tharaka oral literature had in it, aspects that ensured checks and measures not just for society behavior but how to curb conflict.

Circumcision as a rite of passage is introduced in the story "The Lion, the Hare and the Monkeys" narrated by Nyaga, which like some of the stories analyzed above, contains an aspect of food shortage. In the story, the hare and the lion are friends and like in the narrative "The Lion and the Cow" discussed earlier, they often go hunting together. However, when the lion gets ill the hare cannot look for enough food to satisfy the lion. Out of fear of becoming lion's food since the little the hare hunted could not satisfy the lion, the hare tricks the monkeys and they are all killed by the lion. The hare tells the monkeys that they were stinking because they were not circumcised. Thus, he organizes for them to enter the cave one by one to be 'circumcised', only to become lion's food. This narrative appropriates the traditional rite of circumcision which stands out as an important rite in the Tharaka society because the monkeys do not hesitate to go for it. The hare's calculated blackmail demonstrates the attitude towards uncircumcised characters in this society - like the monkeys the uncircumcised feel guilty for not having the cut. As shown earlier, Pearson argues that in any society, there is need to integrate people so that they can belong, by for example giving them something they can hold in common such as values and believes. In the above narrative circumcision represents one of the values of the Tharaka community and that is why the monkeys fall into the hare's trap since they believe in being correctly integrated into the values of the community. While Malinowski's (1944) idea about culture is that of being an instrumental apparatus that man uses to cope with specific problems that face him in his environment in the course of satisfaction of his needs, in this narrative we notice that some characters tended to use such cultural weapons to their own advantage, subsequently causing suffering and violence to the community. This can be read as a survival tactic for hare, and by extension the community members, as put forward by Kuper and Kuper (1985).

In the story "Utethio's Family and the Giant" narrated by Nyaga we see marriage systems and economic activities like farming and hunting being carried out between the giant and human beings. It is within these economic activities that conflict comes up. The story also shows that children, men and women were liable to the tricks of the ogre/giants and wisdom was rather individualized because it is the children who outweigh the malice of the giant. The giant eats all the family members but Njagi who builds his house in a tree, from where his two children trick and kill the horrendous giant. Similarly, the story "A man and a Giant" exposes the search for food and blacksmithing, while in "The ogre and the girl" we witness hunting and gathering in the community, where the girls encounter the wrath of the ogre in the forest. The three stories explicate the encounter between humans and animals and the conflict between the two, showing that the selfishness and gluttony of the ogres brought conflict between them and the human race. The character of the ogre represents those terrible characters in the society who bring conflict to the peaceful coexistence causing others suffering and sometimes death. These stories are also important in demonstrating part of the thesis of this study; that oral literature 
in any community helps in presenting, re-narrating the experiences of a people and acting as a memory reservoir for the community.

Similarly, the story "The chosen ones" by Nthiga is about the ogre, domestic animals and human beings and like some of the stories discussed earlier, it exposes economic activities like hunting and livestock keeping. Societal rites like marriage also come clear, while there are fights between the characters. In addition, we see rewards for good deeds. In this story, an old man lived with grandsons and there was an animal that was eating their goats and cows. The boys had vowed to kill this animal but it becomes clear that this animal would change itself into a beautiful lady and therefore would not be recognized easily, bringing in the issue of magic and its power of deception. One day the ogre visits the boys while they are out with cows and claims that the world belonged to the ogres and not humans. When eventually the ogre starts to killing the cows, the boys swiftly fight back and kill it. The screams of the boys attracted the neighbors and on witnessing the boys' accomplishment, the neighbors honored them as great members of the society. The king then rewarded the boys by allowing them to marry his two daughters. This narrative shows interpersonal conflicts between the characters, which were sometimes resolved through violence encounters, just like we saw in the story "Karauki and the Raiders". This point will be elaborated further in the next section. The narrative also demonstrates that hard work was rewarded in this community. Reward was therefore a way of encouraging hard work. This action by the king is line with Parsons' (2005) argument that there is need to develop social mechanisms to manage tensions, motivate people and resolve interpersonal conflicts within any cultural institution, thus the rewarding of the boys.

From the narratives discussed above, it is clear that the Tharaka community was involved in economic activities like peasant farming, pastoralism, blacksmithing, raiding, hunting and gathering. They also believed in magic and traditional medicine, and practised rites of passage like circumcision. Such activities embedded in traditional memory reservoir can be used as a backdrop to understand how far modern innovations have transformed the community under study. It is in the interaction during these activities that relationship between different characters is realized and also the kind of punishments and rewards given become visible. Conflict, which is discussed in the next section, also came out through these interactions.

\section{A SUMMARY NOTE ON CONFLICT IN THE NARRATIVES}

As argued earlier, oral narratives are seen in this paper as exposing the kind of conflict that existed in Tharaka community, its cause and the resolution. In many of the narratives analyzed here, conflict ensues commonly from lack of food or during the search for food. For example, as hinted earlier in the narrative "The lion and the cow" by Munyi, conflict arises when the young ones of the cow and the lion are left at home while the mothers are looking for food because the cow's calf which was older than the lion's serves him little food then a fight ensues and in the process the lion's cub dies creating even a bigger conflict. On arrival the cow runs away to man for protection. This is an etiological narrative but its importance in this scenario is the fact that it reveals that there were food shortages in the Tharaka community. Luck of food also introduces personal conflict in the story "The Lion, the Hare and the Monkeys" where hare is forced to device ways to save himself from the lion's wrath. While this narrative could be useful in showing the importance of circumcision in the society, conflict also creeps in because of hunger in the lion's and hare's household. As a major necessity in a person's life food determines how health a person is and therefore the reason it creates conflict in the event that it is not available. Some of the conflicts that arise in these narratives become permanent therefore explaining the source of enmity in the society. For instance, the cow runs away to man for protection and lions continue to search for cows to revenge. Another conflict is also 
evident in the story "The Hen and the Eagle" narrated by Nkuru, which presents a lesson about being careful while handling people's property. The eagle lends the hen a razor, which she loses, bringing enmity. The narrative explains that subsequently, while mother hen continues to look for the razor, shown by the way it scratches the ground, the eagle has never forgiven her for losing it and is always on revenge mission: the eagle picks the hen's chicks for food. Such a narrative explicates why conflicts sometimes persisted in some communities; because some people were careless like the hen, others were the unforgiving type like the eagle.

Unlike the conflict that we see between the cow and the lion and between the eagle and the hen, which arise from the relationship between the two animals involved in the story, the conflict in "The snake and the Frog" is brought about by characters who are not part of the friendship circle; outsiders who intrude their farm. This conflict can be read as a metaphor of conflict between the Tharaka community and the neighboring communities who intruded into their territory to raid [read steal food]. Such intrusion is also seen in the conflict exemplified in "Ciari and Kamankura" and "Karauki and the Raiders", brought about by raiding. The end result in these narratives demonstrates that it was the community's responsibility to solve crisis within and without. In some of the narratives like in "Utethio's Family and the Giant" the resolution of conflict or the counter action is shown to be through trickery to overcome the enemy.

Generally we realize that conflict arose in the Tharaka community from the daily activities that they were involved in. Their weapons, it seems, served as a source of power for guarding the society.

\section{CONCLUSION}

This study has revealed that the Tharaka community was involved in different economic activities and these activities helped not just to understand the community, but they in addition helped to reveal the types and causes of conflicts that existed in the community. Characters and the relationship between characters are powerful metaphors of societal occurrences regardless of whether these characters are human or animals. Different characters allow us to look into the activities of the Tharaka community and the specific conflict that ensued and how such conflicts were resolved and why some of the conflicts never ended.

In most instances in the narratives, the source of conflict seems to be what Bayart (1993) calls "the politics of the belly"; the right of capture and distribution of property. Food shortage and famine seems to be the dominant cause of conflict in this society because the shortage introduces other aspects that cause conflict like theft [of food and cows]. This could be an indication that the community was constantly under the threat of famine. These intercommunity conflicts are exemplified in the contemporary society where innovations make the attacks even more complicated. Traditional narratives on conflicts can therefore be read like microcosms of the modern larger inter-country conflict.

It is therefore crucial to preserve traditional African oral narratives because they are not just memory reservoirs for the community knowledge but they act as lessons for the human society. These lessons, for example, include collective responsibility in solving problems, genuine reward of hard work and punishment of the evil persons without discrimination.

\section{References}

Adejumo, A. 2009. Technologizing Oral Texts: Achieving Yoruba Oral Literature through New Technological Media. LUMINA, Vol. 20, No2. pp1-16.

Bayart, J. 1993. The State in Africa: The Politics of the Belly. London: Longman. 
Muriungi, C. K. (2019). Representation of Socio-Economic Activities and Conflict in Traditional Oral Narratives of the Tharaka People in Kenya. Advances in Social Sciences Research Journal, 6(7) 385-392.

Chesaina, C. 1994. Oral Literature of the Kalenjin. Nairobi: Educational Publishers Ltd.

Joshua Project (1994). People and Language Detail Report: The Tharaka of Kenya.

https://joshuaproject.net/assets/media/profiles/text/t15463_ke.pdf (Date of access 20 ${ }^{\text {th }}$ March 2016).

Kuper, A., and Kuper, J. (1985). The Social Science Encyclopedia. London: Routledge \& Kegan Paul.

Malinowski, B. (1944). A Scientific Theory of Culture and other Essays. Chapel Hill, N. Carolina: The University of North Carolina Press.

Mirambo, I. 2010. Oral Literature of the Sukuma. P113-122. Accessed on 05/03/2016 http://www.folklore/vol26/mirambo.pdf.

Parsons, Shitemi, N. 2009. Discourse on Semiotic and Functional Perspective of Narratology. The Journal of African Studies. Vol 2, No 8. pp78-108.

START. Al-Shabaab Attack on Garissa University in Kenya https://www.start.umd.edu/pubs/STARTBackgroundReport_alShabaabGarissaU_April2015.pdf (Date of access 12 $2^{\text {th }}$ March 2016).

www.sociology.org.uk2005 Functionalism: Basic Principles. (Date of access $12^{\text {th }}$ July 2016). 